\title{
Decoupling from Moral Responsibility for CSR: Employees'Visionary Procrastination at a SME
}

\author{
Tina Sendlhofer ${ }^{1}$ (])
}

Received: 8 February 2018 / Accepted: 2 May 2019 / Published online: 16 May 2019

(c) The Author(s) 2019

\begin{abstract}
Most studies of corporate social responsibility (CSR) have focused on the organisational level, while the individual level of analysis has been treated as a 'black box' when researching antecedents of CSR engagement or disengagement. This article offers insights into a small and medium-sized enterprise (SME) that is recognised as a pioneer in CSR. Although the extant literature suggests that the owner-manager is crucial in the implementation of CSR, this study reveals that employees drive CSR. The employees in the focal firm voluntarily joined forces based on their shared perception of moral responsibility for CSR and they developed strict targets to be achieved by 2030. Despite their strong ethical and moral perspective when enacting CSR, they disengaged from their moral responsibility for CSR in various contexts. This paper contributes to the theory of moral decoupling by uncovering a novel context of disengagement- 'visionary procrastination'. Visionary procrastination is suggested to be a particularly relevant context of disengagement when individuals perceive moral responsibility for CSR. Moreover, by delivering insights into the antecedents of employee-initiated CSR on the organisational level, this study adds to the growing body of literature on the micro-foundations of CSR.
\end{abstract}

Keywords Moral responsibility for CSR $\cdot$ Moral decoupling $\cdot$ Small and medium-sized enterprises

\section{Introduction}

Many empirical studies of corporate social responsibility (CSR) share a common focus-the quantitative scrutiny of CSR in multinational corporations (MNCs) — even though they adopt a wide variety of theories (Aguinis and Glavas 2012; Lockett et al. 2006; Wickert and De Bakker 2018). The focus on MNCs may be rooted in the fact that CSR is often assumed to emerge from external pressures, such as exposure to stakeholder demands (e.g. Bice 2017). Although studies of MNCs as global actors in the global economy are relevant, studies of small and medium-sized enterprises (SMEs) merit equal attention (Spence 2016). As more than 99\% ${ }^{1}$ of companies in the European Union are SMEs (EC 2017) and as SMEs account for $70 \%$ of industrial pollution (Hillary 2004), SMEs constitute a crucial gateway to positive social and environmental impacts. While the majority

Tina Sendlhofer

tina.sendlhofer@phdstudent.hhs.se

1 Mistra Center for Sustainable Markets (Misum), Stockholm School of Economics, Holländargatan 32, 11359 Stockholm, Sweden of SMEs are said to demonstrate little engagement in CSR, some authors find that smaller firms are not necessarily lagging behind in the organising of it (Baumann-Pauly et al. 2013; Spence 2016).

Smaller companies typically have more informal organisational characteristics, such as weak structures of control, few hierarchical levels, limited access to resources, and many of the positions in these organisations are often crossfunctional (e.g. Egels-Zandén 2017a). Subsequently, SMEs normally do not have their own CSR departments. Therefore, whether an organisation establishes CSR policies might depend on individual employees. If, in fact, employees act as proponents for CSR and assume responsibility for enacting CSR through their work roles, then concepts such as moral responsibility (e.g. McMahon 1995; Velasquez 1983, 2003) can offer distinct insights into the micro-foundations of CSR.

The micro-foundations of CSR have been conceptualised as central drivers of responsible business activities (Aguinis and Glavas 2012; Costas and Kärreman 2013; Godfrey and Hatch 2007; Jones Christensen et al. 2014; Jones et al. 2018). These micro-foundations are psychological and sociological mechanisms that underlie CSR on the individual

\footnotetext{
$195 \%$ in OECD countries (OECD 2000).
} 
level-also referred to as micro-CSR - and they can elucidate macro-level CSR processes (Aguinis and Glavas 2012). Internal members of an organisation, such as employees, play a vital role in this regard (Girschik 2018; Ha-Brookshire 2017), as they are particularly impactful in the framing and establishment of CSR (Collier and Esteban 2007; Kaler 2009). Furthermore, the extant literature treats moral responsibility - the individual's sentiments about the right thing to do-as a potential driver of CSR engagement (Eriksson and Svensson 2016; Ha-Brookshire 2017). However, tensions arising from inconsistencies between the morality and actions of individual employees may impede moral responsibility (Elkington 1998). Such tensions can be triggered by conflicts between conventional business logics, such as financial outcomes, and business logics that are driven by more ethical motives (Ibid). These tensions give rise to a dissonance between one's own cognitive motives and actions, which has been termed 'moral decoupling' (Eriksson and Svensson 2016).

This article seeks to shed light on CSR micro-foundations by asking the following question: How is moral responsibility part of CSR enactment in SMEs? The findings indicate that CSR may be initiated by the employees' perceptions of moral responsibility for CSR. However, their sense of moral responsibility for CSR is constrained, as the analysis reveals a variety of decoupling mechanisms in employees' daily tasks that result in unethical behaviour on the organisational level.

This article contributes to the theory of moral decoupling by uncovering a novel context of disengagement: 'visionary procrastination'. The study also informs the growing stream of literature on the micro-foundations of CSR by adding an understanding of the SME context as well as contexts of disengagement that may jeopardise SMEs' integration of CSR (Aguinis and Glavas 2012; Jones Christensen et al. 2014; Vázquez-Carrasco and López-Pérez 2013). Furthermore, the article offers insights into the significant role played by employees when they perceive that their organisation is responsible for enacting CSR (Spence 2016; von Weltzien Hoivik and Shankar 2011). Lastly, by demonstrating why employees enact CSR instead of how CSR affects employees, this article informs the extant literature about employeefocused micro-foundations of CSR (Avery et al. 2007; Crilly et al. 2012; Girschik 2018; Jones et al. 2018; Jones and Rupp 2016).

\section{Literature Review}

\section{The Moral Responsibility of Organisations}

Business ideologies shape an organisation's internal and external activities (Zald 2000). In other words, business ideologies serve as the roadmap for organisations' moral principles (Oliver and Johnston 2000). Traditionally, the emphasis has been on the organisation's responsibility to ensure financial success and economic growth, while moral considerations have been ignored (Ulrich 2008). This view suggests that individual managers or employees do not need to reflect on aspects of morality in their decision making or their actions in organisational contexts (Ibid). Subsequently, the organisational outcome in terms of the extent of (un) ethical behaviour is conditioned (Sims 1992).

However, when an organisation chooses a roadmap for decision making based on moral responsibilities rather than economic responsibilities (Ha-Brookshire 2017), the organisation's ethical behaviour becomes manifested in social systems, such as CSR policies, codes of conduct, or ethical guidelines (Eriksson et al. 2013). Jones and Ryan (1997, p. 664) define moral responsibility as the "accountability of one's chosen actions that advance or retard moral purpose". Morality has been found to be socially constructed (Bandura 1999), highly context specific, and highly personal (Bevan and Corvellec 2007). In an organisational context, this definition presupposes that morality is applicable to the individual members of organisations, such as employees (Dempsey 2015; Dubbink 2015; Hess 2013). Thus, in this article, the concept of 'morality' refers to the individual employee's own perception of the 'rightness' or 'wrongness' of her or his behaviour (see Ha-Brookshire 2017).

\section{Employees' Perceptions of Moral Responsibility Within an Organisation}

Previous research indicates that organisation's moral responsibility and individual moral responsibility are interrelated (Bovens 1998; LoMonaco-Benzing and Ha-Brookshire 2016; Poonamallee and Joy 2018). For instance, Constantinescu and Kaptein (2015) theorise a mutual enhancing relationship between the moral responsibility of the individual and the organisation. If an organisation has clear structures and goals that are aligned with moral responsibility, then the employee's moral responsibility will reinforce the organisation's moral responsibility and vice versa.

When establishing a link between the moral responsibility of the employee and the organisation's moral responsibility, it is necessary consider the fact that organisations are, in essence, social institutions (Aranzadi 2013). Thus, the organisation's informal culture, including shared values, beliefs and knowledge (Solomon 1992), interacts with the individual employee's moral responsibility (Ha-Brookshire 2017; Kaptein 2011). Groups and teams serve as the foundation of organisations (Lowell 2012), and they can affect the moral responsibility of individual employees (Sims 1992). This means that individual employees enact their moral responsibilities differently through groups (Ibid). Building 
on the concept of groupthink (Bales 1950; Janis and Mann 1977), Sims (1992) suggests that, despite their personal morals, individuals might be more inclined to make unethical decisions when in a group. More precisely, groups or organisations can develop mechanisms and collective patterns that decouple from individual employees' morals (Ibid). Hence, the individual employee's perception of moral responsibility is not the only basis for her or his ethical decision makingthat decision making is also highly interdependent with the organisational environment (Trevino 1986).

\section{Employees' Moral Responsibility for CSR}

CSR has been defined as "the integration of an enterprise's social, environmental, ethical and philanthropic responsibilities towards society into its operations, processes and core business strategy in cooperation with relevant stakeholders" (Rasche et al. 2017, p. 6). As a primary stakeholder, an employee of an organisation is both a main beneficiary of and an agent for CSR (Collier and Esteban 2007; Girschik 2018; Kaler 2009; Rupp et al. 2006). Yet, relatively limited attention has been paid to employees' own engagement in establishing CSR (Aguilera et al. 2007; Gond et al. 2017; Slack et al. 2015). More specifically, most of our knowledge is based on studies that scrutinise the effects of CSR leadership, CSR policies, or CSR programmes on employees. Such studies cover, for instance, CSR in relation to the recruitment of new employees, talent management, job satisfaction, employee motivation, and personal fulfilment (Gond et al. 2017; Jones et al. 2018; Jones and Rupp 2016; Rupp and Mallory 2015). However, the question of how employees establish CSR, either individually or in a group, merits equal attention (Aguinis and Glavas 2012; Chadee et al. 2011). Girschik (2018) conceptualises employees as proponents of CSR. She applies the analytical lens of internal activism and finds that organisational members develop new responsibilities from the inside by transforming the organisation's business practices. Thus, whether the organisational outcome is (un)ethical is determined by the (un)ethical behaviour of individual employees (Collier and Esteban 2007).

The spectrum of a single employee's decision responsibilities is often broader in flatter organisations than in hierarchical organisations. In such cases, whether the organisation engages in CSR may depend on individual employees' perceptions of moral responsibility for CSR. In this regard, I adapt Ha-Brookshire's (2017) interpretation of moral responsibility and define the employee's moral responsibility for CSR as "the feeling or articulation of individual employees to make decisions and take action in order to promote CSR based on their own beliefs and their perceptions of the right thing to do".

\section{Moral Decoupling from CSR in Organisations}

The concept of moral decoupling, which has been defined as "a psychological process, used to separate moral from transactions so that materials, information, and money may be transferred, while the moral responsibility is diffused or separated from the transaction" (Eriksson et al. 2013, p. 728), explains behaviour that deviates from moral responsibility on the individual level. Bandura (1999) suggests eight specific decoupling mechanisms: moral justification, euphemistic labelling, advantageous comparison, displacement of responsibility, diffusion of responsibility, disregard for or of distortion of consequences, dehumanisation, and attribution of blame (see also Barsky 2011; Thornberg and Jungert 2013).

Although most studies of moral decoupling have been conducted in relation to war, violence or bullying (Moore 2008), moral decoupling also occurs in organisational contexts (Bandura et al. 1996; Eriksson et al. 2013; Eriksson and Svensson 2016). Recent studies have explored these moral decoupling mechanisms as processes that impede perceptions of responsibility in the context of sustainable supply chain management (Eriksson et al. 2013; Eriksson and Svensson 2016). Egels-Zandén (2017b) examines moral disengagement in value chains and finds that corporate managers shift their responsibility boundaries depending on the type of supplier. They rationalise these variances in assuming responsibility for their suppliers through moral disengagement. However, employees' disengagement from moral responsibility for CSR has not been addressed in this line of research.

Kant (1991) suggests that morality can be viewed as either a flexible or an inflexible duty. From this perspective, moral decoupling can be understood as a context of disengagement in which the individual employee takes detours from her or his moral responsibility for CSR. For instance, if the moral responsibility for CSR is a flexible duty, then the employee can retain her or his perceived moral responsibility for CSR while simultaneously decoupling from it.

\section{Methods and Data}

Given the dearth of studies about CSR in SMEs as well as employee involvement in CSR (see Jones et al. 2018), this study utilises a qualitative case study method (Marshall and Rossman 2014). This research strategy allows researchers to gain in-depth insights into the focal phenomenon and to access idiosyncratic qualities of the studied unit (Maxwell 1992; Yin 1981). With the intention of obtaining data-rich insights (Glaser and Strauss 1967; Patton 1990), a case is usually purposefully sampled according to certain criteria, such as extreme, unique, longitudinal, revelatory or critical 
(Yin 2003). Thereafter, qualitative observations give the researcher the opportunity to gather novel insights for theory development. The selection of informants who have been personally involved in the focal phenomenon gives rise to a qualified data set (Ghauri 2004). The individual employee is at the heart of the investigation in this study. Glavas (2016) confirms that studying the micro-foundations of CSR among individual employees is useful in revealing the idiosyncrasies of CSR on the organisational level.

\section{The Case}

Simplicity, ${ }^{2}$ founded in the 1990 s and headquartered in Stockholm, is one of Sweden's leading apparel companies. Simplicity's EBIT was EUR 3.8 million and, at the time, it employed 153 people (Allabolag 2017). In 2016, the company was internationally recognised with an award for its outstanding commitment to sustainability (Simplicity website).

By taking the lead in sustainable innovation and development, Simplicity has developed an idiosyncratic profile in the local industry. Several CSR-related projects have been launched: Reduce, Repair, Recycle, Re-use; Fair Wear Foundation; and The Chemical Group. The borders between these groups have merged over time in terms of personnel and work tasks. Consequently, the umbrella group Pioneers ${ }^{3}$ was born, which is dedicated to driving CSR on all levels at Simplicity. The Pioneers aim to be a creative and unconventional group that challenges Simplicity's business model and supports the transformation of that business model into an entirely sustainable and circular business model by 2030 . In order to achieve this goal, the Pioneers have worked out a specific timeline, known as the '2030 Commitments'. One of the group's core activities is to challenge business partners to fulfil the company's new in-house criteria for the use of sustainable materials and for transparency in procurement. In addition, in an attempt to generate the knowledge needed to achieve the 2030 Commitments, the group tests new supply chains, methods for communicating with consumers, inhouse procedures and potential changes to other aspects of the business model (simplicity website).

Simplicity's sustainability director leads the Pioneers. She or he deems it important to make participation in the Pioneers voluntary and to ensure that the group involves employees from a variety of functional areas, thus making the group a cross-functional team. The team had a total of 20 members in 2017 , including the sustainability director,

\footnotetext{
2 This is a fictional name assigned to the SME to protect its identity.

${ }^{3}$ This is a fictional name for the group. The Pioneers use the terms 'CSR' and 'sustainability' interchangeably. I predominantly use CSR in the text to describe the phenomenon at hand.
}

four lower-level managers (e.g. fabric managers) and 15 nonmanagerial employees (e.g. design assistants). No explicit hierarchy exists in the group, as every participant's opinion is equally valued (Observation 1 ).

Simplicity experienced financial and personnel difficulties in 2016 and 2017. Its long-term CEO left the organisation in 2016 and was replaced in May 2017. According to the new CEO, the fact that she or he was an outsider recruited to the organisation was important. Since then, top management has reconsidered the otherwise unquestioned shift towards a new, sustainable and circular business model, although Simplicity continues to position itself as an industry leader in sustainability.

\section{Data Collection}

The initial challenge was to gain access to simplicity. The SME was chosen for this study because of its size and because it was the industry leader in sustainability. Hence, it could be regarded as a "critical case" (Yin 2003, p. 40) as it challenged the prevailing assumption that SMEs lag behind in organising CSR. Furthermore, the study of employees was expected to inform the scholarly conversation about the role of employees in enacting CSR in organisations (Jones et al. 2018). In line with other critical cases, this study hopes to refocus future research on the active role of employees in CSR enactment (Yin 2003). Hence, an examination of the SME's idiosyncrasies offers an opportunity to advance our understanding of the micro-foundations of CSR.

The data were collected through continuous informal and formal dialogue with employees between October 2016 and October 2017. Both primary and secondary data were collected through: (1) 17 semi-structured interviews with current and former Pioneers members as well as the CEO; (2) observations of six workshops focused on developing the Pioneers; (3) two observations of follow-up meetings called to discuss the development of the Pioneers; (4) archival data, such as two organisational reports, four sustainability reports and the organisation's website (see Table 4 in Appendix 1). The interview guideline was inspired by the phenomenon of sustainable business models and by efforts within the organisation to drive sustainability in a rather unsustainable industry. The main topics included interpretations of sustainability and responsibility in connection with employees' roles, the role of the relatively small organisation in driving internal and external change in the apparel industry, supply chain relationships, opportunities and challenges associated with sustainable business models, the organisation's role as a leader in the apparel industry, and transparency within and across businesses with special focus on sustainability-related topics. The semi-structured interview guide can be found in Table 5 in Appendix 1. 

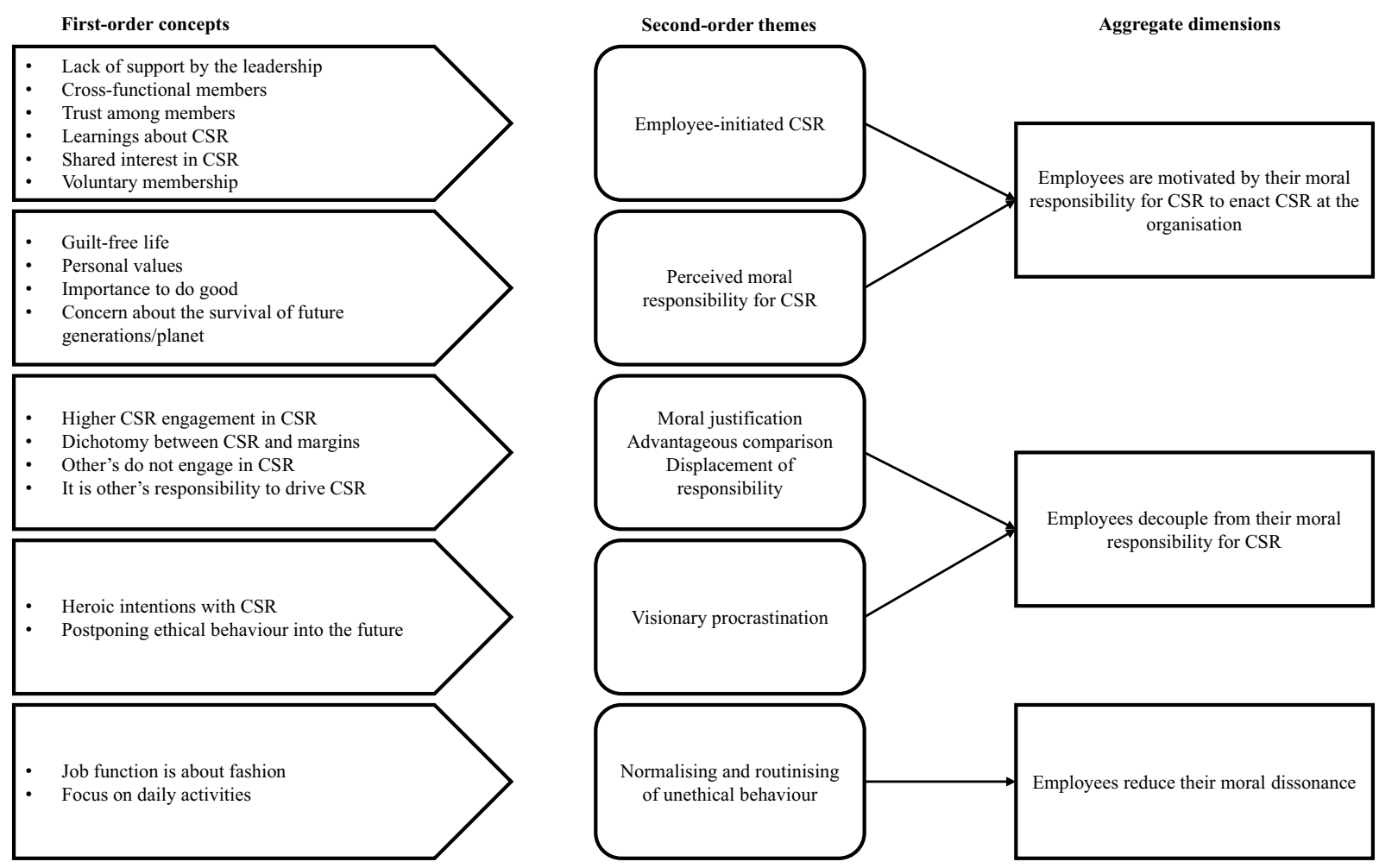

Fig. 1 Data structure

\section{Data Analysis}

The first step was to transcribe the recorded interviews. I then coded all of the primary and secondary material with the support of the Nvivo data-management program. The coding process was aligned with Gioia's methodology for inductive research (Gioia et al. 2013). As illustrated in Fig. 1, this process allows for more transparent and rigorous analyses of qualitative data.

The coding process consisted of four steps. I first focused on primary data sources, as they were expected to provide the most valuable insights into motivations and associated actions. Furthermore, this material was open-coded, such that the analysis concentrated on the "identifying, categorizing, and describing of phenomena found in the text" (Gibbert and Ruigrok 2010, p. 721). In practice, every line of the transcribed material was open-coded. More specifically, I reviewed the data for information on why informants engaged with CSR questions in their jobs. I also reviewed the data for possible linkages between voluntary engagement and job responsibilities. These first-order codes are descriptive codes (Punch 2014), which means that interviewees' statements were used to name them. For instance, the following statements were coded as 'personal values': "It [sustainability] is really important, but this is more of a personal view" (Interviewee 2) and "It [sustainability] is about personal values" (Interviewee 5). The descriptive codes were used to sort the data into 18 segments and served as the basis for higher-order coding.

Second, observations and secondary data were then used as background data and for triangulation (Jick 1979). Thereafter, I started an initial inferential analysis in which I added supportive or contradictory data to the concepts. The code "disengagement from CSR" serves as an example of the triangulation process. The first step of the analysis revealed the following comment: "The consumer does not care about sustainability" (Interviewee 7). This statement was triangulated with observational data, such as "consumers are not shifting from purchases based on inspiration to purchases based on need" (Interviewee 9 in Observation 2).

Third, I continued to develop more specific themes, which I labelled second-order themes. At this stage, the interpretative process started, which involved moving between data and theory in an iterative manner. These second-order themes are pattern codes that bring the data together into seven more meaningful units. For instance, when the data revealed that employees disengaged from CSR, the literature by Bandura (1999) and Eriksson and Svensson (2016) was used to analyse the decoupling mechanisms, some of which were more common than others. This process was reified by continuing the data analysis and letting novel concepts, such as the pattern code 'visionary procrastination', evolve. The 
exhaustive iteration between data and theory also allowed for the data to be linked to the literature on moral dissonance (Lowell 2012) and helped to capture daily activities that the employees used to deal with moral tensions.

Lastly, the second-order themes were analysed through higher-inferential coding, which led the way to three aggregate dimensions that explain the findings from the study in the best possible way. In the following section, the findings are presented as they were uncovered in the analytical process.

\section{Findings}

This section covers this study's four main findings and serves as the empirical starting point for the analysis of the role of moral responsibility in CSR enactment in SMEs. First, the interviewees presented a consistent picture of how CSR is enacted by a specific group of employees. Second, the members of that group explained that their motivations for enacting CSR were based on a perceived moral responsibility to engage in CSR. Third, the findings show that despite these employees' perceptions of moral responsibility, they decoupled from that responsibility in their daily decision making. Fourth, the employees applied normalising and routinising tactics to overcome moral-behaviour tensions.

\section{Employees Enact CSR in the Organisation}

Simplicity did not originally have a visible CSR profile. Instead, it managed to establish a CSR profile in the years leading up to the study. The organisation was one of the first smaller companies in the local industry to publish CSRfocused reports. When CSR began to take centre stage in 2015, the Pioneers group was born. This employee-driven initiative brought together everyone who believed that CSR, also referred to as the 2030 Commitments, should be developed on the organisational level.

By 2017, a total of $15 \%$ of staff across all departments had voluntarily joined the Pioneers. One of the Pioneers describes the voluntary aspect of membership: "It was not a manager telling me 'you should do this or that'. Actually, I built much of the role that I have today in the Pioneers and at Simplicity myself" (Interviewee 7). ${ }^{4}$ Organised meetings and workshops are held to administer the Pioneers. Most of the Pioneers' members are employees with little strategic decision-making power. As such, they are considered to be rather weak stakeholders. According to its members, the following qualities are crucial for the Pioneers: equal

\footnotetext{
${ }^{4}$ Additional supportive material can be found in Table 6 in Appen$\operatorname{dix} 2$.
}

terms, access, trust, open dialogue, learning culture, regular meetings, diffusion of knowledge and transparency. The Pioneers not only share similar ideas about CSR but they also perceive the group as vital for the future of their organisation. One interviewee describes their experience in a meeting with other Pioneers as follows:

That is also what was so amazing yesterday-even though everyone comes with her or his own [sustainability] strategy and agenda, we [the Pioneers] solve it together as we work toward the 2030 Commitments. [This happens] on every side and we do not do it to please someone else. We do it for our [the Pioneers] sake. We do it for the future of our business -that is when you get full commitment. (Interviewee 1)

Notably, neither employed shareholders nor the CEO take part in the Pioneers. In fact, some Pioneers report that Simplicity's leadership has little interest in promoting the organisation's CSR plans. Nonetheless, the Pioneers are dedicated to driving CSR on the organisational level. The decision to enact CSR through a group might be interpreted as an attempt to go against management's directives. One Pioneer states that the CEO's ideas for the company concern establishing an e-commerce platform and promoting sales instead of furthering the integration of CSR:

The question should be 'How can e-commerce support sustainability?'. They are not separate paths. That could be really interesting and something that could differentiate us [Simplicity]. We can work toward e-commerce, which is the CEO's priority, but incorporate some sustainability models [e.g., renting, repairing] into it. However, right now, it is just about e-commerce, e-commerce, e-commerce. (Interviewee 17)

When management was asked about the role of the 2030 Commitments in the organisation and their potential implications for the business, the Pioneers' intentions were belittled. The CEO indicated that CSR is not a tool that will ensure the future of the business, but it is to increase sales. This mirrors the Pioneers' perceptions of the CEO's priorities:

It is not enough to say 'let us make Simplicity $100 \%$ sustainable'. That statement will not make a difference. We need to grow and make more consumers buy our products instead of others. That is, at least, what motivates me - to go beyond just being sustainable and still sell our products. (Interviewee 16)

Employees who have greater decision-making power at Simplicity include the members of the design team, the creative director and the CEO. Thus, the merging of individual CSR projects into one group can be understood as an attempt to establish a more influential voice in the diffusion of CSR 
throughout the organisation and to engage colleagues who hold greater decision-making power.

\section{Employees Motivated by Moral Responsibility for CSR}

The data analysis indicated that most employees who are part of the Pioneers are motivated by their perceived moral responsibility for CSR. This stretches from their daily jobs to the general role of Simplicity as a company. As morality is a highly person-specific concept, each respondent expresses her or his moral responsibility for CSR in slightly different terms. While some employees associate their moral responsibility for CSR with mindfulness of their decision making and behaviour, others interpret it as an instrument for enabling future generations to live an equally good life: "CSR means being mindful about the water usage and chemicals" (Interviewee 10) ${ }^{5}$ and "We have to take care of the futurethe children and their future" (Interviewee 6).

Some interviewees link their involvement in CSR with moral reasoning that is associated with 'doing the right thing' or 'avoiding doing the wrong thing'. This reasoning is connected to either Simplicity and the activities associated with the organisation or to the individual's purpose and related activities:

I think [working with CSR] is very important. As a company, I think it is sometimes difficult to be innovative [for CSR]. However, it is the only way forward for us [Simplicity] and the industry because it would be wrong to continue what we have been doing for so long. (Interviewee 2)

Another factor that typifies the employees' perceived moral responsibility for CSR is the desire to live a guilt-free life. One Pioneer relates working with CSR to the avoidance of guilty feelings: "I do not want to have guilty feelings [from not working with CSR]" (Interviewee 5).

Notably, the evidence on the Pioneers' perceived moral responsibility for CSR might lead to the belief that this group of employees strictly abides by the CSR targets stipulated in the 2030 Commitments. However, the members of the Pioneers revealed that they viewed their perceived moral responsibility for CSR as a flexible rather than an inflexible duty. Consequently, members of the Pioneers disengaged from their moral responsibility for CSR.

\footnotetext{
5 Additional supportive material can be found in Table 7 in Appen$\operatorname{dix} 2$.
}

\section{Employees Decouple from Their Moral Responsibility for CSR}

The voluntary nature of the Pioneers combined with their moral responsibility for CSR may lead to the assumption that the organisational outcome is ethical behaviour. Thus, it was surprising to find that members of the Pioneers decouple from their moral responsibility for CSR. Evidence of decoupling emerged in all interviews. Generally, members of the Pioneers find it difficult to live up to their moral responsibility for CSR in their daily decision making. One reoccurring narrative concerns the tension between the intent to do the right thing and the financial situation at Simplicity. Across all represented positions, the members of the Pioneers feel that it is impossible to carry out their moral responsibility for CSR, as a variety of business contexts do not allow for it. Most of these contexts of disengagement are covered by Bandura's (1999) eight decoupling mechanisms. While all decoupling mechanisms were evident in the data analysis, one novel and three relatively dominant decoupling mechanisms were notable. Table 1 provides example statements related to each of the observed mechanisms. In connection with the employee-driven CSR context, each item includes a description of how the previously contextualised decoupling mechanisms (e.g. Eriksson and Svensson 2016) have been interpreted in this study.

Three decoupling mechanisms were relatively dominant in the data: moral justification, advantageous comparison and displacement of responsibility. Moral justification occurs when employees "justify their behaviour to themselves before taking actions" (Eriksson and Svensson 2016, p. 285). In other words, although employees regard themselves as moral agents for CSR, they view their failure to live up to their perceived moral responsibility for CSR as part of business as usual. One interpretation of the relative dominance of moral justification is that Simplicity's employees are embedded in an organisation in which more conventional goals, such as financial success, have been deeply integrated since its foundation. In fact, the involvement of employees in CSR and the development of the 2030 Commitments have become more concrete since 2015 . Therefore, it might be difficult for employees to overcome well-established organisational activities that work against their CSR targets.

Advantageous comparison occurs when employees' "harmful behaviour is made to appear good in contrast to an alternative" (Eriksson and Svensson 2016, p. 286). This means that employees may compare their own behaviour with that of their competitors, even if their competitors show little engagement in CSR. Advantageous comparisons as a dominant decoupling mechanism can be interpreted as a consequence of the generally CSR low standards across the industry. Indeed, Simplicity has received recognition of its role as a pioneer in CSR in the industry. This external 
Table 1 Illustrative quotes for decoupling from moral responsibility for CSR

Decoupling from moral responsibility for CSR

Moral justification

When a person before engaging in irresponsible conduct justify to herself or himself that their actions are morally acceptable, such as participating in irresponsible practices in good cause for the company's financial outcome.

"We know that we are not perfect. We need to be able to be a commercial business after all". (Interviewee 13)

"Sustainability is very important of course, but it is also a question of money. Because most often, the fabrics are a bit more expensive if you decide for sustainable options. Then you also need bigger volumes since the minimums are higher. This is difficult for us [Simplicity]". (Interviewee 14)

"There is a dichotomy between being a commercial business: Between reaching good prices and achieving sustainability goals". (Interviewee 13)

"I am responsible for our margins, to receive the goods in the store in time, and not to buy too much. We do not want to end up with too big volumes. There are a lot of things that have to be in the same loop. If I could decide, then all fabrics should be sustainable. But then the margins would go down and we would need bigger volumes due to minimums. Maybe we would get even longer lead times. You have to look into every piece and every style: How can you do it with this piece and is it possible for this style? Where can we add the sustainability?" (Interviewee 15)

"I am sure that we do not act like this deliberately [unsustainable], like 'Oh here work kids, but it is cheaper, so we produce there'. You are in a way tied to the trust that you give to them [suppliers]. You simply cannot go there every day and check on them". (Interviewee 13)

"You know you need it [sustainability] from all angles. The customers are not educated. I do not think that it will come from them. We are waiting for that, and it is probably not coming for another 15 years, or 10 maybe. I think maybe companies, like us, need a due diligence. That you really scrutinise yourself: What are you doing?" (Interviewee 7)

\section{Euphemistic labelling}

When a person changes the label and words of action so that the actions are sanitised.

"It [sustainability] is a 'positive competition' part. To compete with the other companies". (Interviewee 15)

"Sustainability is a 'hygiene factor"”. (Interviewee 16)

\section{Advantageous comparison}

When a person compares her or his own irresponsible action with an alternative that is worse.

"We [Simplicity] try more than the others [competitors]". (Interviewee 2)

"As long as our competitors perform worse, we can allow ourselves too". (Interviewee 13 in Observation 2)

"We are leading [in CSR] in the industry". (Interviewee 1, Observation 1)

"We are the better choice [for sustainability]". (Interviewee 4, Observation 1)

"Others [competitors] are doing worse". (Interviewee 16)

"Others [competitors] are doing less, it [sustainability] is more like a branding thing". (Interviewee 5)

"Everybody has a smartphone in their pocket. And smartphones are even worse [less sustainable]. And even if you go back the supply chain of a smartphone, I think that the production is even worse than for our knitted sweater made in China". (Interviewee 7)

"Then we look at other brands and they are not really doing anything. They have such a long way to go. Then, you are thinking of the footprint that we are currently leaving as a fashion industry. It is scary. I find that there are so many companies that are not doing anything". (Interviewee 9)

Displacement of responsibility

When a person does not consider herself or himself to be the agents of irresponsible behaviour. These agents are instead other organisations and leadership of the organisation.

"She or he has more power. She or he is the head of design. She or he can take actions [for sustainability]". (Interviewee 3)

"I mean it is up to the designer which quality [sustainable/unsustainable] they want to work with. In the end, it is for sure them to decide what quality they would like to work with". (Interviewee 9)

"The suppliers have to take care of this [sustainability]". (Interviewee 8 in Observation 2)

"The consumer does not care about sustainability". (Interviewee 7)

"I met with the person who was the creative director at that time and she or he said: But it is fashion first. She or he is only sustainable if it meets our fashion vision. And in most cases, it does not. So, we always choose the fashion”. (Interviewee 17)

"That is why it is not going to be Simplicity to solve it alone. The more people are demanding it [sustainability], the more pressure will be on the brands too. Then there will be more pressure on the suppliers, because it is about their survival. Then they need to change. But, it might take time as well". (Interviewee 16)

Diffusion of responsibility

When a person's sense of agency gets obscured by diffusing personal accountability. It is applicable in group decision making when everybody is responsible, but no one feels responsible for it. 
Table 1 (continued)

"I cannot decide it [sustainability] alone". (Interviewee 2 in Observation 4)

"It [sustainability] is the task of the government to regulate". (Interviewee 4)

"Black is the least sustainable, because you need a lot of chemicals in order to produce the colour. So, black is not so good for the environment. But on the other hand, it would be a very versatile garment that you can mix and match with lot of things. You are also using it probably a longer time. Therefore, we made a choice together that the colour should be black". (Interviewee 6)

\section{Disregard or distortion of consequences}

When a person ignores, minimises, distorts, or disbelieves negative results of the irresponsible activities.

"Production [of clothing] is per definition unsustainable". (Interviewee 5)

"The question is, whether the product is beautiful. How should you act as a company? Another factory may be very good regarding the sustainability agenda, but they make a lousy product". (Interviewee 5)

\section{Dehumanisation}

When the victim of actions is stripped from human properties and to portray these victims as mindless beings with no human worth.

"I mean like, yeah, we want this at the half-cost, so we are developing it with countries from where the kids are bleeding with their fingers for it. We do not think about that, because this would never happen". (Interviewee 11)

\section{Attribution of blame}

When a person views herself or himself as faultless victims driven by their adversaries to irresponsible actions by forcible provocation.

"The consumers do not ask for it [sustainability]". (Interviewee 7)

"But I have also worked on two seasons now and I have not seen all the transparency. I am struggling to find some of these fabric makers. They are not new fabric suppliers either. We are getting there, but that is also because we are small”. (Interviewee 10)

(See Aquino et al. 2007; Bandura 1999; Bandura et al. 1996; Eriksson et al. 2013; Vollum and Buffington-Vollum 2010)

recognition of the organisation's CSR work may be one factor that makes it reasonable for employees to justify their deviating behaviour by constructing negative comparisons with their competitors.

The third dominant context of disengagement is the displacement of responsibility. This occurs when employees "believe their irresponsible behaviour is an outcome of external circumstances" (Eriksson and Svensson 2016, p. 286). In other words, employees might believe that they lack the agentic ability (i.e. decision-making power) to enact CSR. Instead, they assign the necessary agency to other organisational members. This displacement of responsibility can be understood as a consequence of decision discretion in their job roles. Only a small number of Pioneers hold managerial positions and might, therefore, carry accountability for decisions. Moreover, in conjunction with the change in Simplicity's top management, a new hierarchy appears to have entered the organisational structure. Some Pioneers have experienced a displacement of responsibility, as their decisions have been suppressed since the change in top management. In that situation, employees view top management as the agent for certain behaviours.

The novel context of disengagement is labelled 'visionary procrastination', which is proposed as an additional mechanism for moral decoupling from CSR that consists of two interacting elements: 'visionary' and 'procrastination'. This decoupling mechanism is evident throughout the interviews and it is particularly relevant in the context of CSR. The term 'visionary' relates to the fact that the moral responsibility for CSR is framed as behaving in extraordinarily ethical manner. This takes the form of activities that are so good that they could eventually contribute to grandiose outcomes (e.g. saving the planet and future generations). The term 'procrastination' is associated with the futuristic orientation of such heroic CSR endeavours. More specifically, employees create a situation in which they allow themselves to behave unethically in the present and transfer the perceived moral responsibility for CSR to the distant future. One employee describes this decoupling through visionary procrastination with an emphasis on 'visionary': “The Pioneers' CSR ideas should become normal business [for Simplicity] by 2030" (Interviewee 1 in Observation 1). Another employee expresses this decoupling through visionary procrastination with the emphasis on 'procrastination': "[Deciding to use an unsustainable fabric] because you [Simplicity] does not have to be sustainable today" (Interviewee 10 in Observation 4). Table 2 presents additional supportive evidence of visionary procrastination.

In summary, the findings demonstrate that the Pioneers, despite their perception of moral responsibility for CSR, struggle to fitting CSR into decision making in their respective job roles. Various contexts of disengagement are evident, including the novel decoupling mechanism of visionary procrastination. An additional observation is that employees apply various tactics to cope with their indifferent behaviour, such as normalising and routinising. These tactics can be interpreted as the result of moral dissonance with regard to the moral responsibility-behaviour tension. 
Table 2 Illustrative quotes for visionary procrastination

Visionary procrastination

Visionary

Projecting heroic ethical behaviour as part of the moral responsibility for CSR

"All of them are-you know—most of them at least know that it [being sustainable] is a big goal for us, including the planet". (Interviewee 4)

"We will transform the regular business, and want to revolutionise the business to better [sustainable] business". (Interviewee 1, Observation 1)

"I want to be part of doing as good as we can. I feel really proud of Simplicity, because we are doing a lot [sustainability related]. I think that we have higher ambitions about what we aspire to do than we are able to do, because it costs money". (Interviewee 7)

"Looking at one material at the time, our plan is to make our entire collection sustainable by 2030". (Website 2018)

"I think where we can make the biggest difference is to having presence in the area of the global fashion world. So even if you have a sustainable company, there are millions of other companies that work-you know unsustainable — and do not do what we do. It is also to inspire other companies to have a much more mindful consumption. I think that is also where you can see a bigger impact”. (Interviewee 16)

\section{Procrastination}

Postponing heroic ethical behaviour as part of moral responsibility for CSR into the distant future

"I want to be straightforward. At the end of the day you try to consider all aspects [sustainability] in your daily work. But this is not the standard decision process in the industry. Thus, it is too expensive to choose sustainability today". (Interviewee 6)

"I think that it comes down to the struggle to make money and earn our margins. So, the sustainability part has to go into the future of some things". (Interviewee 16)

"You can also choose to work completely idealistic today. But then, no one will buy your products and your company will be bankrupt, which is not being very sustainable". (Interviewee 13)

"Because we only have a certain amount of money today; budget for the sustainability area. And you know, we have to adjust accordingly". (Interviewee 5)

Table 3 Illustrative quotes for moral dissonance

Moral dissonance

\section{Normalising}

"If a larger competitor changes their production toward sustainability, it has greater influence than changing our small company's production toward sustainability". (Interviewee 14)

"When it concerns larger production, then one should produce in Asia. Producing in Asia has maybe a negative connotation: Brand infringement and human rights. This is certainly true in a way. But they (Asia) have the capacity to produce high quantities and the fabrics are very good [quality]". (Interviewee 5)

"It is normal that at a larger competitor, the suppliers would produce their [larger competitor] sustainable fabric ideas. But we are just too small, so we have to choose what is offered to us". (Interviewee 10)

\section{Routinising}

"In my line of work, responsibility is to do not go over budget, respect time planning and assure quality". (Interviewee 15)

"My task is to focus on the design of clothes, accessories and shoes". (Interviewee 14)

"And that is crucial for me to calculate the costs [of sustainable fabric]. I think we need to do that. I have to set goals: This is the price we should have, this is the quantity we should produce, and this is the margin that we should focus end up with". (Interviewee 15)

\section{Employees Reduce Their Moral Dissonance}

The tactics applied by the employees who decouple from their moral responsibility for CSR reveal that such decoupling occurs relatively often. In fact, they indicate a pattern of continuous escalation. Lowell (2012) conceptualised the tactics that individuals apply to overcome perceived moralbehaviour tensions. The normalising of unethical behaviour is a method that employees use to reduce the significance of their decision (Ibid), while the routinising of unethical behaviour occurs when the employee focuses on the details of a decision rather than the overall consequences of that decision (Tsang 2002). For instance, normalising may occur when employees assume that the consequences of their decisions are not significant given Simplicity's relatively small organisational size. Routinising relates to job descriptions that leave out any mention of the 2030 Commitments. Evidence of the normalising and routinising of decoupling from moral responsibility of CSR is presented in Table 3.

In summary, the first finding demonstrates that the employees initiate Simplicity's CSR activities, while the company's leadership, including the CEO, resists the business's transformation towards the 2030 Commitments. The second finding shows that employees perceive a moral 
responsibility for CSR and have developed a CSR commitment for the company. The third finding reveals that this perception of moral responsibility for CSR is flexible, meaning that the employees take detours in many instances, which are captured in various decoupling mechanisms. A novel contribution emerges here-visionary procrastination as a context of moral disengagement. Visionary procrastination allows employees to decouple in the present by transferring the fulfilment of their moral responsibility for CSR to the distant future. The various techniques of decoupling from moral responsibility may induce tensions between moral responsibility for CSR and behaviour. The fourth finding builds on this tension by showing that moral decoupling can lead to normalising and routinising, through which employees can reduce their exposure to moral dissonance.

\section{Discussion}

\section{Employee-Initiated CSR in SMEs}

As the case highlights, employees may enact CSR in SMEs. In the case company, a number of employees formed a crossfunctional group with the primary objective of completing a transformation towards a sustainable business model by the year 2030. These employees hope to do so by integrating CSR activities into their daily jobs. Research indicates that CSR activities in SMEs are frequently designed in ways that link them to core business functions (Baumann-Pauly et al. 2013). Furthermore, the looser control structures, flatter hierarchies, and informal communication channels (Baumann-Pauly et al. 2013; Fassin 2008; Jenkins 2004, 2006, 2009; Spence 2007) in the SME context may act as components that enable employees to establish CSR. For Simplicity, this means that employees have access to more fertile soil to reach their CSR targets and they do not have to follow formal decision-making paths when altering organisational procedures. Hence, these employees have fewer formal hurdles to overcome (Fassin 2008).

The extant literature stresses the need for ethical leadership to sustain CSR in organisations (Lips-Wiersma and Morris 2009) and emphasises the role of the owner-manager in the undertaking of CSR in SMEs (Jenkins 2009). In fact, the importance of the owner-manager is highlighted not only in relation to sustaining CSR but also for establishing it (Dincer and Dincer 2013). CSR usually roots itself in the personal ethics and value systems of the owner-manager. The process at Simplicity appears to differ in this regard, as employees try to sustain CSR by attracting company leaders to join the group, including the CEO, the head of design and the creative director. In a related stream of literature, employees who are CSR protagonists are regarded as internal activists (Girschik 2018) with the capacity to transform existing business practices by mobilising other members of the organisation (Wickert and De Bakker 2018). In their efforts to mobilise the company's leadership, the employees at Simplicity focus on sustainable solutions, including the economic feasibility manifested in the 2030 Commitments.

Although Simplicity's leadership generally failed to become engaged in CSR, the employees were allowed to develop the 2030 Commitments. Previous studies label this outcome 'passion with an umbrella' (Scully and Segal 2002,), which occurs when the corporate machinery curtails the passion of organisational members (Wright and Nyberg 2017). Zald (2000) suggests that the leadership's ideology must align with the internal movement in the organisation in order for the movement to be sustained. A failure by leadership to engage in CSR may reflect the weak impact of the internal pressure exerted by employees. External pressures, such as those exerted by consumers, might be more effective at ensuring that CSR is introduced on the organisational level (Basu and Palazzo 2008).

The group members share similar ideas about the SME's responsibilities as an actor in the industry. Through the formation of a group, the employees attempt to create a stronger voice for enacting the 2030 Commitments on behalf of the SME. These commitments are based on the employees' values and beliefs. Thus, the employees build an organisational culture around CSR. An established organisational culture can be instrumental for CSR-oriented decision making, as individuals have limited freedom to deviate (Hejjas et al. 2018; Lowell 2012). For instance, an organisational culture can differentiate between moral actions that would harm an organisation's performance and immoral actions that would boost an organisation's financial outcome. Hence, as guidelines for an organisational culture, the 2030 Commitments represent a built-in roadmap for moral decision making on the organisational level (Oliver and Johnston 2000).

\section{Moral Responsibility for CSR}

Employees' perceptions of moral responsibility for CSR are revealed in their attempts 'to do the right thing' when enacting CSR. However, their CSR engagement does not enhance their careers or raise their salaries. The employees are willing to put extra work and time in for CSR, which implies that their motivation for engaging in CSR is connected to their personal ethics rather than to a business rationale (see Aguilera et al. 2007). The employees' aim is to live without guilt and they hope to contribute to the greater good, especially the survival of future generations and the planet. For these employees, this is the right thing to do. In other words, these perceptions constitute their moral compass. The employees expressed their personal motivations for participating in CSR in slightly different ways, often from a more personal point of view (Slack et al. 2015) or as agents for the SME (Collier and Esteban 2007). 
Even though the employees have strong motives for engaging in CSR, their moral responsibility cannot necessarily be regarded as a perfect duty (Ha-Brookshire 2017). The employees have formalised CSR goals for the organisation, but the internal procedures seem to maintain the rather conventional business model. As a result, the employees find their organisation to be hypocritical, as organisational behaviour is inconsistent with the CSR goals (Ha-Brookshire 2017). Consequently, these employees increasingly circumvent CSR. The majority continue to work towards the common goals of the 2030 Commitments, but they allow themselves to take detours. As many of their ambitions lie in the distant future, it is difficult to evaluate whether CSR consists of 'flexible duties' for the employees or if detours in the form of decoupling are signs that they are separating themselves from their own moral responsibility for CSR. If the employees viewed their CSR commitment as an 'inflexible duty', then the SME could be considered a perfectly sustainable organisation (Ha-Brookshire 2017).

\section{Decoupling from Moral Responsibility for CSR Through Visionary Procrastination}

In this study, a novel context of disengagement was identified-visionary procrastination. In relation to the $2030 \mathrm{Com}-$ mitments, visionary procrastination occurred when employees defined ambitious CSR goals for the distant future. The visionary component entails a type of heroic goal setting, such as undertaking a substantial business model transformation or saving the planet's resources for future generations. The theory of 'self-fulfilling prophesies' (Merton 1948; Schaltegger and Burritt 2018) predicts that the way in which visions of the future are discussed has an impact on the steps that are taken in the present. However, the mental capability to travel in time might be compromised by the distance to the future goal. Hence, in this decoupling mechanism, the interplay between the visionary component and the procrastination component is vital. Procrastination occurs when a heroic goal cannot be reached until the distant future and indicates that the employees perceive no urgent need to implement CSR. Societal concerns that are part of CSR usually have relatively longer time horizons, while business concerns often emphasise short-term thinking (Slawinski and Bansal 2015).

In this study, the shifting of the CSR goals into the distant future occurs at the cost of implementing CSR-related activities in the present. The relatively long CSR timescale is a common characteristic of CSR and sustainability reports. It allows employees to acquire enough knowledge and to mobilise the resources needed to complete a sustainable business model transformation, while it also allows them to take detours and engage in moral decoupling in decision making. Long timelines are often seen in a positive light in
CSR discussions, as CSR typically intends to reach beyond financial objectives. However, visionary procrastination may have unintended consequences (e.g. a failure to meet the case company's 2030 Commitments).

In addition to visionary procrastination, the study confirms the presence of other moral decoupling mechanisms (Bandura 1999) that are used to justify a drift in behaviour. The organisational environment shapes contexts for disengagement that are used against economic reasoning. In particular, the tension between CSR goals and financial goals has been frequently addressed, giving rise to a variety of terms, such as 'window dressing' and 'green washing' (e.g. Bromley and Powell 2012; Feix 2017). These point to structural barriers, such as deeply embedded organisational processes and industry-specific contexts, including short production cycles and opaque supply chains (Eriksson et al. 2013). The most salient contexts of decoupling are moral justification, advantageous comparison and displacement of responsibility. For many of the employees, it seemed acceptable to act against their own moral responsibility on behalf of the organisation, while others justified the drift from their moral responsibility by comparing themselves to less ethical competitors. Lastly, some employees did not feel they possessed the agency necessary to enact their moral responsibility for CSR.

Finally, the extant literature on moral decoupling (e.g. Eriksson et al. 2013; Eriksson and Svensson 2016) has not addressed whether this phenomenon occurs in isolated instances or is a pattern of continuous escalation of unethical behaviour. Through decoupling, employees can be exposed to tensions between moral responsibility and behaviour. Previous studies have suggested various ways of reducing this tension (Lowell 2012). In this study, employees revealed that they normalised and routinised their unethical behaviour to deal with these tensions. The significance of these tactics might be low, especially if normalising and routinising only occur in isolated instances (Lowell 2012). However, on the organisational level, frequent usage of such behaviours can have significant implications for the transformation. Given that the Pioneers group represents $15 \%$ of all of the SME's employees and the fact that many group members exhibited patterns of normalising and routinising, the group's own goals for the 2030 Commitments appear to be in jeopardy.

\section{Contributions and Conclusion}

This article answers the call for more research into moral decoupling in organisations (Johnson and Buckley 2015). It contributes to our understanding of moral decoupling mechanisms by uncovering the novel concept of visionary procrastination. Visionary procrastination arises when CSR developed on the organisational level involves heroic goal 
setting, but the fulfilment of those goals is postponed to the distant future. More generally, the discussion of this disengagement technique adds to the literature on the microfoundations of CSR by offering an initial theoretical base for micro-foundations that might enable or hinder CSR on the organisational level (Jones et al. 2018). Furthermore, the study illustrates that consideration of moral decoupling is useful when analysing how employees make decisions that violate their perceived moral responsibility for CSR without imposing self-sanctions. By demonstrating that moral responsibility is part of employee-initiated CSR, this study contributes to the literature on moral responsibility for CSR (Ha-Brookshire 2017). The findings suggest that moral responsibility can act as an enabling factor for CSR but the implementation of CSR may be impeded by the fact that employees view this moral responsibility as a flexible duty.

Moreover, by linking the two related bodies of literature about moral decoupling (Bandura 1999; Eriksson et al. 2013) and moral dissonance (Lowell 2012), this study explains how employees' deal with the tensions that can arise from the decoupling of their moral responsibility. Such decoupling can have long-term implications for the organisation's CSR outcomes.

Lastly, this study contributes to the literature on the microfoundations of CSR, i.e. micro-CSR, by uncovering antecedents that enable and jeopardise the enactment of CSR among employees (Jones et al. 2018; Ones and Dilchert 2012). More specifically, instead of focusing on the values and motivations of the owner-manager in relation to CSR (Kaesehage et al. 2014; Vives 2006), CSR is presented as an outcome of employees' motivations. Moreover, as this study shows that CSR is motivated by employees' perceptions about 'the right thing to do', it offers insights about the significant role played by employees owing to their perceptions of moral responsibility for CSR in their workplace. Although some employees, including the CEO, do not seem to share this perception, the enactment of CSR in form of the 2030 Commitments has continued. This suggests that the role of the owner-manager is not necessarily central for the implementation of CSR, although it might be an enabler or a disabler in this regard.

\section{Conclusions}

In conclusion, this article has illustrated the relevance of moral decoupling for studies of employee-driven CSR. The findings presented here highlight the importance of enhancing our understanding of micro-foundations of CSR by reversing the analytical direction. The focal SME had a clear commitment to CSR, which emerged independent of external pressures and performance-driven objectives. In fact, a specific group of employees in the organisation, most of whom were lower-level employees, perceived a moral responsibility to implement CSR in the SME and, therefore, enacted CSR on the organisational level.
The link between individual employees' moral responsibility for CSR and organisational CSR is particularly important in the context of smaller organisations. As these organisations have more informal structures of control and culture, the significance of the individual employee's perception of moral responsibility for CSR can increase. In this case, the organisation's moral responsibility can be thought of as mirroring the employee's moral responsibility and vice versa. Thus, the moral responsibility of the individual employee can be regarded as an antecedent of (un)ethical organisational behaviour in smaller organisations. However, employees' endeavours to enact CSR can be conditioned through various decoupling mechanisms. The novel concept of visionary procrastination suggests that the employees justified their deviating activities with the idea that they would meet their moral responsibility for CSR in the distant future. As CSR was perceived as a future goal of 'doing the right thing', employees did not view procrastination as 'doing the wrong thing'.

Finally, the employees formed a group in order to produce a stronger mandate for enacting CSR within the organisation. Nevertheless, mechanisms such as groupthink (Sims 1992) may mean that the group can decouple itself from individual employees' morals. Although this study recognises the relevance of group dynamics, it has focused on the individual employee rather than collective patterns. Future research is needed to shed light on group dynamics and decoupling mechanisms in employee-driven CSR in SMEs. In the present study, the disengagement mechanisms slowed down or even jeopardised the employees' CSR activities. The ways in which leadership, such as owner-managers or CEOs, might be motivated to engage in employee-instigated CSR remains a topic for future research.

Acknowledgements I acknowledge the constructive comments from the participants at Misum Internal Seminar Series at Stockholm School of Economics, where an earlier version of this paper was presented. Special thanks go to the thoughtful and thorough comments by Andreas Rasche. I also want to thank my interviewees for sharing their time and insights with me. Lastly, the developmental comments by the reviewers and guiding support by the editor contributed to the improvement of this article's quality.

Funding This study was funded by Mistra Future Fashion.

\section{Compliance with ethical standards}

Conflict of interests Tina Sendlhofer declares that she has no conflict of interests.

Open Access This article is distributed under the terms of the Creative Commons Attribution 4.0 International License (http://creativeco mmons.org/licenses/by/4.0/), which permits unrestricted use, distribution, and reproduction in any medium, provided you give appropriate credit to the original author(s) and the source, provide a link to the Creative Commons license, and indicate if changes were made. 


\section{Appendix 1}

See Tables 4 and 5.

Table 4 Data table

\begin{tabular}{ll}
\hline Interviewee 1 & Sustainability director \\
\hline Interviewee 2 & Design assistant women \\
Interviewee 3 & Design assistant women 2 \\
Interviewee 4 & Product manager, environmental sustainability manager \\
Interviewee 5 & Supply chain manager, social sustainability manager \\
Interviewee 6 & Marketing communications \\
Interviewee 7 & Sales manager/store owner \\
Interviewee 8 & Logistics \\
Interviewee 9 & Wholesale manager Sweden/Finland \\
Interviewee 10 & Fabric and trim manager \\
Interviewee 11 & Digital tech lead \\
Interviewee 12 & Product buyer \\
Interviewee 13 & Head of design (men) \\
Interviewee 14 & Buyer for jersey \\
Interviewee 15 & Financial controller \\
Interviewee 16 & CEO \\
Interviewee 17 & Fabric and trim manager (follow-up) \\
Observations & Observation 1, Observation 2, Observation 3, Observation 4, \\
& Observation 5, Observation 6, Observation 7, Observation 8 \\
Reports & Simplicity sustainability report: 2016, 2015, 2014, 2013, 2012 \\
\hline
\end{tabular}

Table 5 Illustrative questions for semi-structured interviews

\begin{tabular}{|c|c|}
\hline Topic & Example questions \\
\hline Defining responsibility, sustainability & $\begin{array}{l}\text { In connection to your job role: what does responsibility mean to you? } \\
\text { In connection to your job role: what does sustainability mean to you? }\end{array}$ \\
\hline Job-role & $\begin{array}{l}\text { What is your current role at Simplicity, what functions do you fulfil? } \\
\text { In what CSR projects are you currently involved? } \\
\text { How did you get affiliated with CSR projects? } \\
\text { Are you part of the Pioneers? } \\
\text { Why are you part of the Pioneers? } \\
\text { Why are you not part of the Pioneers? } \\
\text { Why do you think others should be part or not part of the Pioneers? } \\
\text { How do you set and implement CSR goals? } \\
\text { Do you believe you can fulfil the ' } 2030 \text { Commitments'? } \\
\text { What are the challenges in your daily job role to fulfil the Pioneer's '2030 Commitments'? } \\
\text { Describe your latest decision that you consider 'sustainable' } \\
\text { Describe your latest decision that you consider 'unsustainable' } \\
\text { Do you feel that you are supported in your endeavours by the leadership, e.g. CEO? }\end{array}$ \\
\hline Role of a relatively smaller organisation & $\begin{array}{l}\text { How do you perceive the role of businesses, and Simplicity in more particular, in society? } \\
\text { What are Simplicity's challenges? }\end{array}$ \\
\hline $\begin{array}{l}\text { Role of a smaller organisation to drive change } \\
\text { in the apparel industry }\end{array}$ & $\begin{array}{l}\text { How do you perceive the role of Simplicity for driving change in the industry? } \\
\text { What are the opportunities and challenges with that change? }\end{array}$ \\
\hline Stakeholders, e.g. supply chain relationships & $\begin{array}{l}\text { What role do suppliers play in the industry? } \\
\text { How do suppliers perceive your ' } 2030 \text { Commitments'? } \\
\text { What commitments are easily adapted? } \\
\text { What are the challenges to bring suppliers on board? }\end{array}$ \\
\hline $\begin{array}{l}\text { Opportunities, challenges with sustainable } \\
\text { business models }\end{array}$ & $\begin{array}{l}\text { What are the incentives to develop a sustainable business model? } \\
\text { What challenges come with sustainable business models? }\end{array}$ \\
\hline Role of transparency in the industry & $\begin{array}{l}\text { What is the role of transparency in the industry? } \\
\text { How do you interpret the current practices in the industry, regarding sustainable innova- } \\
\text { tions? }\end{array}$ \\
\hline
\end{tabular}




\section{Appendix 2}

See Tables 6 and 7.

Table 6 Illustrative quotes for employee-initiated CSR

Employee-initiated CSR

Lack of support by the leadership

"And then I met with the person who was the creative director at that time and she or he said: 'Yeah, but it is fashion first'. She or he is only sustainable if it meets our fashion vision. In most cases, it does not meet our vision. So, we always choose the fashion". (Interviewee 17)

"It is really the sustainability director and then a lot of us [Pioneers] who believe in it [sustainability]. When you are talk to the CEO, from the business side, there is not a big push. Actually, the board of directors and the CEO are sort of re-evaluating it and question sustainability. It is what we do, it is part of who we are, it is part of our identity". (Interviewee 10)

"So now we have to go back and look what the price would have been if it was all sustainable or organic. We need to present this to the sustainability director. She or he can present our findings the board of directors, and explain why we did not do the transition to sustainable options. It is so easy to sit in a production meeting and calculating the costs: 'Ok it is going to cost 1.5 Dollars more than a regular fabric, so it does not affect our margin so much. These decisions can be also very short-sighted". (Interviewee 17)

"That is good. But it [resistance to sustainability] is more coming from the top, the creative director. She or he has recently returned to the business. I think that she or he is under a lot of pressure to make a really wow-collection. So, at the very top it has been really a struggle for her or him to feel secure with the choices that she or he has made". (Interviewee 4)

Cross-functional members $\quad$ "I think it is a good way of doing it, because you come from different departments, have different knowledge, and use of it". (Interviewee 14)

"We have a representative from all departments, from logistics, design, pattern, and marketing". (Interviewee 5)

Trust among members $\quad$ "In the whole group [Pioneers] as such, I can say, I trust. There was never a question of distrust". (Interviewee 4)

"I trust everyone [Pioneers]. I don't know really everybody on a private level. But I feel that I can talk and discuss with everyone". (Interviewee 2)

Learning about CSR "The Pioneers are facilitating a learning process about sustainability". (Interviewee 1 in Observation 2)

"I think it [sustainability] is interesting. And also, to learn more with the Pioneers, I guess". (Interviewee 3)

"Then it is maybe not everyone's passion or expertise, but I think that we all share the basic values and interests". (Interviewee 6)

"We [Pioneers] all have a common understanding about how important it [sustainability] is". (Interviewee 1)

"I think that we [Pioneers] are educating the rest of the business [in sustainability] as well". (Interviewee 15)

Voluntary membership "It [I joined the Pioneers] was more like my own initiative". (Interviewee 3)

"I mean we are here [with Pioneers] voluntarily". (Interviewee 5)

Table 7 Illustrative quotes for moral responsibility for CSR

Moral responsibility for CSR

Guilt-free life

Personal values

Importance to do good

Concern about the survival of future generations/planet
"For me as a person it [CSR] is to live in a way that I do not have guilty feelings". (Interviewee 7) "I would regret not thinking about it [CSR]". (Interviewee 11)

"It [sustainability] is really important, but it is more of a personal view". (Interviewee 2)

"It [sustainability] is about personal values". (Interviewee 5)

"And also, you will not attract any people to work in your company if you are doing bad things. So, I think that it is very important to be ethical and do good things. So, it is both a necessity in terms of resources, but also in terms of attitude". (Interviewee 12)

"Then, it is so interesting to hear, that things don't work out. And how that affects the people who are so involved in sustainable topics, like Interviewee 4 or Interviewee 5 who really believe in that there needs to be change". (Interviewee 9)

"I mean we are looking for long-term success, if we want to be in this market in 10 years. Everything will be different. We will not be able to continue to produce in this way. We are, I'd say the whole world. We are quite good at what we are doing. But the whole world cannot consume the way we are and just emptying the world and not caring about the future, the children and their future. It will simply be not enough resources for all the people in the world. If we want to be in the market in 10 years, then it is a necessity to have been trying out new things. Then, I think also the attitude among people. More and more, nobody wants to be associated with bad companies". (Interviewee 6) 


\section{References}

Aguilera, R. V., Rupp, D. E., Williams, C. A., \& Ganapathi, J. (2007). Putting the $\mathrm{S}$ back in corporate social responsibility: a multilevel theory of social change in organizations. Academy of Management Review, 32(3), 836-863.

Aguinis, H., \& Glavas, A. (2012). What we know and don't know about corporate social responsibility: A review and research agenda. Journal of Management, 38(4), 932-968.

Allabolag. (2017). Bolagsöversikt. https://www.allabolag.se/55646 98586/Simplicity. Accessed 14th December 2017.

Aquino, K., Reed, A., II, Thau, S., \& Freeman, D. (2007). A grotesque and dark beauty: how moral identity and mechanisms of moral disengagement influence cognitive and emotional reactions to war. Journal of Experimental Social Psychology, 43(3), 385-392.

Aranzadi, J. (2013). The natural link between virtue ethics and political virtue: The morality of the market. Journal of Business Ethics, 118(3), 487-496.

Avery, D. R., McKay, P. F., \& Wilson, D. C. (2007). Engaging the aging workforce: the relationship between perceived age similarity, satisfaction with co-workers, and employee engagement. Journal of Applied Psychology, 92(6), 1542-1556.

Bales, R. F. (1950). Interaction process analysis: Theory, research, and application. Reading, MA: Addison-Wesley.

Bandura, A. (1999). Moral disengagement in the perpetration of inhumanities. Personality and Social Psychology Review, 3(3), 193-209.

Bandura, A., Barbaranelli, C., Caprara, G. V., \& Pastorelli, C. (1996). Multifaceted impact of self-efficacy beliefs on academic functioning. Child Development, 67(3), 1206-1222.

Barsky, A. (2011). Investigating the effects of moral disengagement and participation on unethical work behavior. Journal of Business Ethics, 104(1), 59.

Basu, K., \& Palazzo, G. (2008). Corporate social responsibility: A process model of sensemaking. Academy of Management Review, 33(1), 122-136.

Baumann-Pauly, D., Wickert, C., Spence, L. J., \& Scherer, A. G. (2013). Organizing corporate social responsibility in small and large firms: Size matters. Journal of Business Ethics, 115(4), 693-705.

Bevan, D., \& Corvellec, H. (2007). The impossibility of corporate ethics: For a Levinasian approach to managerial ethics. Business Ethics: A European Review, 16(3), 208-219.

Bice, S. (2017). Corporate social responsibility as institution: A social mechanisms framework. Journal of Business Ethics, 143(1), $17-34$.

Bovens, M. (1998). The quest for responsibility: Accountability and citizenship in complex organisations. Cambridge, UK: Cambridge University Press.

Bromley, P., \& Powell, W. W. (2012). From smoke and mirrors to walking the talk: Decoupling in the contemporary world. Academy of Management Annals, 6(1), 483-530.

Chadee, D., Wiesner, R., \& Roxas, B. (2011). Environmental sustainability change management in SMEs: Learning from sustainability champions. International Journal of Learning and Change, 5(3-4), 194-207.

Collier, J., \& Esteban, R. (2007). Corporate social responsibility and employee commitment. Business Ethics: A European Review, 16(1), 19-33.

Constantinescu, M., \& Kaptein, M. (2015). Mutually enhancing responsibility: A theoretical exploration of the interaction mechanisms between individual and corporate moral responsibility. Journal of Business Ethics, 129(2), 325-339.

Costas, J., \& Kärreman, D. (2013). Conscience as control-managing employees through CSR. Organization, 20(3), 394-415.
Crilly, D., Zollo, M., \& Hansen, M. T. (2012). Faking it or muddling through? Understanding decoupling in response to stakeholder pressures. Academy of Management Journal, 55(6), 1429-1448.

Dempsey, J. (2015). Moral responsibility, shared values, and corporate culture. Business Ethics Quarterly, 25(3), 319-340.

Dincer, B., \& Dincer, C. (2013). Corporate social responsibility decisions: a dilemma for SME executives? Social Responsibility Journal, 9(2), 177-187.

Dubbink, W. (2015). A moral grounding of the duty to further justice in commercial life. Ethical Theory and Moral Practice, 18(1), $27-45$.

EC. (2017). SMEs. http://ec.europa.eu/growth/smes/business-friendlyenvironment/sme-definition_sv Accessed December 14th, 2017.

Egels-Zandén, N. (2017a). The role of SMEs in global production networks: A Swedish SME's payment of living wages at its Indian supplier. Business \& Society, 56(1), 92-129.

Egels-Zandén, N. (2017b). Responsibility boundaries in global value chains: supplier audit prioritizations and moral disengagement among Swedish firms. Journal of Business Ethics, 146(3), 515-528.

Elkington, J. (1998). Cannibals with forks: The triple bottom line of 21 st century business. Gabriola Island: New Society.

Eriksson, D., Hilletofth, P., \& Hilmola, O. P. (2013). Supply chain configuration and moral disengagement. International Journal of Procurement Management, 6(6), 718-736.

Eriksson, D., \& Svensson, G. (2016). The process of responsibility, decoupling point, and disengagement of moral and social responsibility in supply chains: Empirical findings and prescriptive thoughts. Journal of Business Ethics, 134(2), 281-298.

Fassin, Y. (2008). SMEs and the fallacy of formalising CSR. Business Ethics: A European Review, 17(4), 364-378.

Feix, A. (2017). Greenwashing revisited: Extending the critique of CSR communication. Academy of Management Proceedings, 2017(1), 15452 .

Ghauri, P. N. (2004). Designing and conducting case studies in international business research. In R. Marschan-Piekkari \& C. Welch (Eds.), Handbook of qualitative research methods for international business (pp. 109-124). Cheltenham: Edward Elgar.

Gibbert, M., \& Ruigrok, W. (2010). The "what" and "how" of case study rigor: Three strategies based on published work. Organizational Research Methods, 13(4), 710-737.

Gioia, D. A., Corley, K. G., \& Hamilton, A. L. (2013). Seeking qualitative rigor in inductive research: Notes on the Gioia methodology. Organizational Research Methods, 16(1), 15-31.

Girschik, V. (2018). Shared responsibility for societal problems: The role of internal activists in reframing corporate responsibility. Business \& Society. https://doi.org/10.1177/0007650318789867.

Glaser, B., \& Strauss, A. (1967). Grounded theory: The discovery of grounded theory. Sociology the Journal of the British Sociological Association, 12, 27-49.

Glavas, A. (2016). Corporate social responsibility and organizational psychology: An integrative review. Frontiers in Psychology, 7, 144.

Godfrey, P. C., \& Hatch, N. W. (2007). Researching corporate social responsibility: An agenda for the 21st century. Journal of Business Ethics, 70(1), 87-98.

Gond, J. P., El Akremi, A., Swaen, V., \& Babu, N. (2017). The psychological micro-foundations of corporate social responsibility: a person-centric systematic review. Journal of Organizational Behavior, 38(2), 225-246.

Ha-Brookshire, J. (2017). Toward moral responsibility theories of corporate sustainability and sustainable supply chain. Journal of Business Ethics, 145(2), 227-237.

Hejjas, K., Miller, G., \& Scarles, S. (2018). "It's like hating puppies!" employee disengagement and corporate social 
responsibility. Journal of Business Ethics. https://doi.org/10.1007/ s10551-018-3791-8.

Hess, K. M. (2013). "If you tickle us...": How corporations can be moral agents without being persons. Journal of Value Inquiry, 47(3), 319-335.

Hillary, R. (2004). Environmental management systems and the smaller enterprise. Journal of Cleaner Production, 12(6), 561-569.

Janis, I. L., \& Mann, L. (1977). Decision making: A psychological analysis of conflict, choice, and commitment. NY: The Free Press.

Jenkins, H. (2004). A critique of conventional CSR theory: An SME perspective. Journal of General Management, 29(4), 37-57.

Jenkins, H. (2006). Small business champions for corporate social responsibility. Journal of Business Ethics, 67(3), 241-256.

Jenkins, H. (2009). A ‘business opportunity' model of corporate social responsibility for small-and medium-sized enterprises. Business Ethics: A European Review, 18(1), 21-36.

Jick, T. D. (1979). Mixing qualitative and quantitative methods: triangulation in action. Administrative Science Quarterly, 24(4), 602-611.

Johnson, J. F., \& Buckley, M. R. (2015). Multi-level organizational moral disengagement: Directions for future investigation. Journal of Business Ethics, 130(2), 291-300.

Jones Christensen, L., Mackey, A., \& Whetten, D. (2014). Taking responsibility for corporate social responsibility: The role of leaders in creating, implementing, sustaining, or avoiding socially responsible firm behaviors. Academy of Management Perspectives, 28(2), 164-178.

Jones, D. A., Newman, A., Shao, R., \& Cooke, F. L. (2018). Advances in employee-focused micro-level research on corporate social responsibility: Situating new contributions within the current state of the literature. Journal of Business Ethics. https://doi. org/10.1007/s10551-018-3792-7.

Jones, D. A., \& Rupp, D. E. (2016). Social responsibility IN and OF organizations: The psychology of corporate social responsibility among organizational members. In N. Anderson, D. S. Ones, H. K. Sinangil, \& C. Viswesvaran (Eds.), Handbook of industrial, work and organizational psychology. NY: Sage.

Jones, T. M., \& Ryan, L. V. (1997). The link between ethical judgment and action in organizations: A moral approbation approach. Organization Science, 8(6), 663-680.

Kaesehage, K., Leyshon, M., \& Caseldine, C. (2014). Communicating climate change-learning from business: challenging values, changing economic thinking, innovating the low carbon economy. Fennia-International Journal of Geography, 192(2), 81-99.

Kaler, J. (2009). An optimally viable version of stakeholder theory. Journal of Business Ethics, 86(3), 297-312.

Kant, I. (1991). The Metaphysics of Morals. (M. Gregory, Trans.) Cambridge, UK: Cambridge University Press.

Kaptein, M. (2011). From inaction to external whistleblowing: The influence of the ethical culture of organizations on employee responses to observed wrongdoing. Journal of Business Ethics, 98(3), 513-530.

Lips-Wiersma, M., \& Morris, L. (2009). Discriminating between 'meaningful work' and the 'management of meaning'. Journal of Business Ethics, 88(3), 491-511.

Lockett, A., Moon, J., \& Visser, W. (2006). Corporate social responsibility in management research: Focus, nature, salience and sources of influence. Journal of Management Studies, 43(1), 115-136.

LoMonaco-Benzing, R., \& Ha-Brookshire, J. (2016). Sustainability as social contract: Textile and apparel professionals' value conflicts within the corporate moral responsibility spectrum. Sustainability, $8(12), 1278$.

Lowell, J. (2012). Managers and moral dissonance: Self-justification as a big threat to ethical management? Journal of Business Ethics, 105(1), 17-25.
Marshall, C., \& Rossman, G. B. (2014). Designing qualitative research. Thousand Oaks, CA: Sage.

Maxwell, J. (1992). Understanding and validity in qualitative research. Harvard Educational Review, 62(3), 279-301.

McMahon, C. (1995). The ontological and moral status of organizations. Business Ethics Quarterly, 5(3), 541-554.

Merton, R. K. (1948). The self-fulfilling prophecy. The Antioch Review, $8(2), 193-210$.

Moore, C. (2008). Moral disengagement in processes of organizational corruption. Journal of Business Ethics, 80(1), 129-139.

OECD. (2000). Small and medium-sized enterprises. http://www.oecd. org/cfe/leed/1918307.pdf. Accessed December 14th, 2017.

Oliver, P., \& Johnston, H. (2000). What a good idea! Ideologies and frames in social movement research. Mobilization: An International Quarterly, 5(1), 37-54.

Ones, D. S., \& Dilchert, S. (2012). Environmental sustainability at work: A call to action. Industrial and Organizational Psychology, 5(4), 444-466.

Patton, M. Q. (1990). Qualitative evaluation and research methods (2nd ed.). Sage: Thousand Oaks, CA.

Poonamallee, L., \& Joy, S. (2018). Connecting the micro to the macro: An exploration of micro-behaviors of individuals who drive CSR initiatives at the macro-level. Frontiers in Psychology. https://doi. org/10.3389/fpsyg.2018.02417.

Punch, K. F. (2014). Introduction to social research: Quantitative and qualitative approaches (3rd ed.). London, UK: Sage.

Rasche, A., Morsing, M., \& Moon, J. (Eds.). (2017). Corporate social responsibility: Strategy, communication, governance. Cambridge, UK: Cambridge University Press.

Rupp, D. E., Ganapathi, J., Aguilera, R. V., \& Williams, C. A. (2006). Employee reactions to corporate social responsibility: An organizational justice framework. Journal of Organizational Behavior: The International Journal of Industrial, Occupational and Organizational Psychology and Behavior, 27(4), 537-543.

Rupp, D. E., \& Mallory, D. B. (2015). Corporate social responsibility: Psychological, person-centric, and progressing. Annual Review of Organizational Psychology and Organizational Behavior, 2, 211-236.

Schaltegger, S., \& Burritt, R. (2018). Business cases and corporate engagement with sustainability: Differentiating ethical motivations. Journal of Business Ethics, 147(2), 241-259.

Scully, M., \& Segal, A. (2002). Passion with an Umbrella: Grassroots activists in the workplace. In M. Lounsbury \& M. J. Ventresca (Eds.), Social structure and organizations in the sociology of organizations (pp. 125-168). New York: Elsevier.

Sims, R. R. (1992). Linking groupthink to unethical behavior in organizations. Journal of Business Ethics, 11(9), 651-662.

Slack, R. E., Corlett, S., \& Morris, R. (2015). Exploring employee engagement with (corporate) social responsibility: A social exchange perspective on organisational participation. Journal of Business Ethics, 127(3), 537-548.

Slawinski, N., \& Bansal, P. (2015). Short on time: Intertemporal tensions in business sustainability. Organization Science, 26(2), 531-549.

Solomon, R. C. (1992). Corporate roles, personal virtues: An Aristotelean approach to business ethics. Business Ethics Quarterly, 2(3), 317-339.

Spence, L. J. (2007). CSR and small business in a European policy context: the five "C" s of CSR and small business research agenda 2007. Business and Society Review, 112(4), 533-552.

Spence, L. J. (2016). Small business social responsibility: Expanding core CSR theory. Business \& Society, 55(1), 23-55.

Thornberg, R., \& Jungert, T. (2013). Bystander behavior in bullying situations: Basic moral sensitivity, moral disengagement and defender self-efficacy. Journal of Adolescence, 36(3), 475-483. 
Trevino, L. K. (1986). Ethical decision making in organizations: A person-situation interactionist model. Academy of Management Review, 11(3), 601-617.

Tsang, J. A. (2002). Moral rationalization and the integration of situational factors and psychological processes in immoral behavior. Review of General Psychology, 6(1), 25-50.

Ulrich, P. (2008). Integrative economic ethics: Foundations of a civilized market economy. Cambridge, UK: Cambridge University Press.

Vázquez-Carrasco, R., \& López-Pérez, M. E. (2013). Small \& medium-sized enterprises and Corporate Social Responsibility: A systematic review of the literature. Quality \& Quantity, 47(6), 3205-3218.

Velasquez, M. G. (1983). Why corporations are not morally responsible for anything they do. Business \& Professional Ethics Journal, 2(3), $1-18$.

Velasquez, M. (2003). Debunking corporate moral responsibility. Business Ethics Quarterly, 13(4), 531-562.

Vives, A. (2006). Social and environmental responsibility in small and medium enterprises in Latin America. Journal of Corporate Citizenship, 21, 39-50.

Vollum, S., \& Buffington-Vollum, J. (2010). An examination of social-psychological factors and support for the death penalty:
Attribution, moral disengagement, and the value-expressive function of attitudes. American Journal of Criminal Justice, 35(1-2), $15-36$.

von Weltzien Hoivik, H., \& Shankar, D. (2011). How can SMEs in a cluster respond to global demands for corporate responsibility? Journal of Business Ethics, 101(2), 175-195.

Wickert, C., \& De Bakker, F. G. (2018). Pitching for social change: Toward a relational approach to selling and buying social issues. Academy of Management Discoveries, 4(1), 50-73.

Wright, C., \& Nyberg, D. (2017). An inconvenient truth: How organizations translate climate change into business as usual. Academy of Management Journal, 60(5), 1633-1661.

Yin, R. K. (1981). The case study crisis: Some answers. Administrative Science Quarterly, 26(1), 58-65.

Yin, R. K. (2003). Case study research: Design and methods (3rd ed.). Thousand Oaks, CA: Sage.

Zald, M. (2000). Ideologically structured action: An enlarged agenda for social movement research. Mobilization: An International Quarterly, 5(1), 1-16.

Publisher's Note Springer Nature remains neutral with regard to jurisdictional claims in published maps and institutional affiliations. 